\title{
LO QUEVEDESCO Y EL POETA COMO HOMBRE ENTRE BASTIDORES EN EL RAYO QUE NO CESA, DE MIGUEL HERNÁNDEZ
}

Scott Dale*

Todos los amigos de la poesía pura deben buscar y leer estos poemas vivos. Los poemas de $\mathrm{El}$ rayo que no cesa tienen su empaque quevedesco, es verdad, su herencia castiza, pero la áspera belleza tremenda de su corazón arraigado rompe el paquete y se desborda, como elemental naturaleza desnuda. Esto es lo excepcional poético. Juan Ramón Jiménez

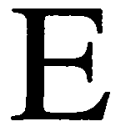

1 poeta murciano Miguel Hernández Giner (1910-1942) abre los caminos poéticos de la posguerra en el bienio 1934-1935 con su obra maestra $E l$ rayo que no cesa, uno de los conjuntos más atormentados de sonetos amorosos en toda la poesía española del siglo XX. Hernández, pionero antifranquista de la poesía social y arquetipo del escritor rural y mítico, publica el famoso poemario con su editor Manolo Altolaguirre en 1936 en la colección Héroe, y nos brinda como primicia su voz auténtica y un estilo auditivo, culto, sincero y armónico. Es verso nacido de las pasiones más íntimas, los fracasos del hombre y la influencia de

* Marquette University. 
DALE, S. Lo quevedesco y el poeta como hombre...

la poética quevedesca; es decir, una poesía inspirada por su esposa Josefina Manresa, su amigo Ramón Sijé, la guerra civil y la poesía de Quevedo. Tras la famosa imagen del "rayo que no cesa" y su refundición intimista de la poética quevedesca, Hernández ve a sí mismo como un ser finito, mortal y determinado por fuerzas superiores que lo impulsan al amor, al dolor, a la soledad y a la muerte. Lo extraordinario de la estética de $E l$ rayo que no cesa es su entusiasmo en la estimación y su profunda apreciación hacia su propia vida.

El rayo que no cesa - un poemario de 27 sonetos, nueve cuartetos iniciales, una silva de trece estrofas irregulares y la famosa "Elegía" dedicada a la muerte de Sijé- es principalmente una obra que desarrolla los temas corporales del amor, la pena y la muerte. Los factores más íntimos que salpican los poemas de $E l$ rayo, las muertes de Sijé, Manresa y, posiblemente, su primer hijo, son las fuerzas que empujan a Hernández a imaginarse una poética tan profunda y emotiva. (Habrá que mencionar, sin embargo, que en la nueva novela El amor y la nada, 2000, de José Luis Ferris, obra que relata cómo vivió Hernández en los años previos a la guerra civil, se asegura que la musa feminina en $E l$ rayo que no cesa no fue Manresa, sino Marcela Duarte, una mujer casada con un diputado de la CEDA en el Madrid republicano.) A pesar de esta posibilidad, lo que queda claro al leer El rayo que no cesa es que las duras experiencias de Hernández, junto con su propia revisión "intimista" de la poética amorosa de Quevedo, son los dos hilos conductores que inspiran cada momento del poemario.

Desde el primer momento de $E l$ rayo, se percibe el tema fundamental: el amor del propio Hernández hacia su amada. En la dedicatoria el poeta escribe, "A ti sola, en cumplimiento de una / promesa que habrás olvidado como / si fuera tuya" (Hernández, 1988, p. 89). Después, el poemario empieza con ritmo apresurado en nueve cuartetos consonantados, el metro popular que empleó tanto Quevedo en sus poemas amorosos, como el "Himno a las estrellas" (c. 1620), obra que fue una influencia evidente en El rayo. (Más adelante identificaré varias huellas temáticas de este conocido poema encontradas en los sonetos de Hernández.) En una palabra, los treinta poemas de El rayo - veintisiete de ellos son sonetos - son ejemplos de una refundición y reinterpretación "intimista" de la actitud abstracta e idealizada de Quevedo hacia los temas del amor, la pena y la muerte.

Los dos últimos tercetos del noveno soneto (p. 97) describen de una manera nítida el dolor del profundo amor de Hernández por Josefina:

Zarza es tu mano si la tiento, zarza, ola tu cuerpo si lo alcanzo, ola, cerca una vez, pero un millar no cerca. Garza es mi pena, esbelta y triste garza, 
sola como un suspiro y un ay, sola, terca en su error y en su desgracia terca.

Como ya ha observado Balcells (1992), se observa aquí una nueva interpretación intimista del amor insatisfecho y apenado, algo muy común en la poética de Quevedo (Balcells, p. 17). Hernández utiliza el tipo métrico más difícil de cultivar - el breve y rígido soneto - pero logra expresar una voz aún más personal e íntima que Quevedo, pues el poeta murciano se refiere a sus propios sentimientos amorosos, a una mujer concreta (Josefina) y a una época específica (el año 1934). Además, emplea un acercamiento más natural e inmediato que el escritor barroco; es decir, la expresión de su amor nunca llega a ser algo idealizado y abstracto, como lo es muchas veces en Quevedo y en el Barroco español en general (Acereda, 1994, p. 39). La fuerza de la pasión personal de Hernández se parece a la de un animal enjaulado en la época de celo; es, en fin, como un "rayo que no cesa", una intensa fuerza no idealizada que no tiene fin. La imagen de este "rayo", como veremos más adelante, representa la actitud poética y el fundamento estético de Hernández. En una palabra, el "rayo" se refiere a la idea de que el amor y la muerte en su propia vida le tormentan sin parar y la mejor manera de ilustrar esta auténtica tortura sentimental es la referencia a un cruel rayo imaginario, una metáfora cargada de sufrimiento humano que desarrolla sus penas en cada verso de su poemario.

Como se puede observar en múltiples estrofas de Quevedo, los dos cuartetos hernandinos ejemplificados anteriormente tienen un claro valor fónico, una seducción de oído, unas rimas interiores y unas repeticiones de palabras en forma de pilares (e.g. zarza, ola, cerca, garza, sola, terca). La idea del amor como autodestrucción la han expresado casi todos nuestros sonetistas clásicos amorosos, con más dulzura Garcilaso, con más bravura Quevedo. En la estética contemporánea de Hernández, sin embargo, lo admirable y lo extraordinario es que son sentimientos biográficos de gran hondura e intimidad que se producen lisamente en los años de un muchacho de veinticuatro años. La temática del amor en $E l$ rayo ofrece los acontecimientos del corazón y de la tierra, radicalmente herido en su felicidad, junto a su estrella guiadora, Josefina, pues escribe, "cerca una vez, pero un millar no cerca" (Hernández 1988, p. 97). Estos dos cuartetos, como casi todos los poemas de El rayo, son testimonios apasionados, transidos de amor y dolor, canciones y llantos adelgazados hasta su último límite de sencillez.

La perspectiva culta e idealizada del amor en el ingenioso poema "Himno a las estrellas" (c. 1620) de Quevedo es una clara influencia temática en El rayo que no cesa (1936), pues en Hernández se percibe una refundición íntima y personal del 
amor quevedesco. El poema barroco es una intensificada reflexión sobre el pensamiento del amor como concepto abstracto del universo. A través de la "estructura simétrica" de su canción lírica, Quevedo intensifica los conceptos platónicos hacia el amor y los coloca dentro de un molde renacentista con la finalidad de sugerir su propio discurso culto del amor como fuerza universal. Esta silva es de una extraordinaria belleza lírica - muy parecida a la poética hernandina - que construye una visión compleja del amor. En este "Himno" nos encontramos con el "poeta de nocturnos," el que se preocupa por la soledad amorosa, el que es inspirado por el "vuelo [de su] pluma temerosa" (v. 2). El destinatario del poema no es una mujer de carne y hueso - como lo es en la poética de Hernández -, sino un sujeto idealizado: "vosotras, estrellas" (v. 1), los astros del universo que se convertirán en signos de aquellas figuras míticas heroicas o enamoradas (Argos, Fortuna, Amarilis y Pancaya) que les dieron nombre. Estos seis versos iniciales del melólogo melancólico nos recuerdan el ambiente oscuro y culto de una noche insomne en otro poema de Quevedo titulado, "Ansia de amante confiado": "La primer moradora / del mundo, sombra ciega, noche avara." Entonces, ya vemos en la primera estrofa el tema central del "Himno": la idea de que el amor es una fuerza abstracta que gira el mundo. La tesis quevedesca sobre el amor en este poema se explica así: estas "estrellas amorosas" dan orden al universo pero, al mismo tiempo, son dañosas "lumbres que enciende[n] triste y dolorosa" (v. 4).

En El rayo que no cesa el amor también organiza el universo, pero Hernández ve el mundo con el corazón, no con la cabeza. Ésta es gran parte de la diferencia entre las dos visiones del amor. Mientras que Quevedo ofrece una interpretación idealizada y abstracta del amor, el poeta contemporáneo expresa el amor a través de su propia pasión, su alma, su impulso creador y nos muestra su intensa inspiración. Las ideas hernandinas saltan, borbotean, se precipitan, se atropellan, mezclando la emoción con el debaneo, la reflexión con el recuerdo y el pasado con el presente. En el último terceto del tercer soneto de $E l$ rayo (p. 92), por ejemplo, se utiliza el hipérbaton y la personificación en una lúcida imagen de su propia alma frustrada y "enjaulada":

un terrón para siempre insatisfecho, un pez embotellado y un martillo harto de golpear en la herreria.

En vez de analizar las cosas de una manera abstracta y casi matemática, como en el poema de Quevedo, el poeta murciano intenta descubrir las dimensiones más profundas del espíritu humano. El primer cuarteto del undécimo soneto ( $\mathrm{p}$. 
DALE, S. Lo quevedesco y el poeta como hombre...

98), por ejemplo, ofrece - como si fuese Bécquer - un buen ejemplo de la ternura y los pudorosos términos de un romántico "encarcelado":

Te me mueres de casta y de sencilla: estoy convicto, amor, estoy confeso de que, raptor intrépido de un beso, yo te libé la flor de la mejilla.

Habla desde su propio corazón, como Shelley en su Defense of Poetry, donde se explica que toda la poesía es la "expresión de la imaginación." Lo que se observa en los versos de El rayo es una potencialidad creadora que transciende los valores de la razón quevedesca. En Hernández se percibe la simpatía humana que despierta y se antepone el valor poético.

La poesía hernandina no descubre ningún misterio del mundo pero, sí, explora el "yo" interior de un poeta con matices románticos, tal como se percibe en la poética de Espronceda, Bécquer, Zorrilla y Rosalía de Castro. Hernández es ejemplo contemporáneo de que en todo poema existe un ser humano "entre bastidores." En El rayo las cosas se asimilan a la actividad propia y el "yo" se identifica con el mundo objetivo y físico; es decir, el pensamiento para él es una voz singular. Es el choque entre el "yo" y el mundo, el instinto y la razón, la vida y el intelecto, o en otros términos, la problemática de la situación histórica y el desgarro de la soledad y sus sentimientos. El primer cuarteto del duodécimo soneto de El rayo (p. 99) que se caracteriza por la rima interior y la repetición del sonido "-encia"- es buen ejemplo del tema de su profunda soledad en el mundo:

Una querencia tengo por tu acento,
una apetencia por tu compañía
y una dolencia de melancolía
por la ausencia del aire de tu viento.

Según el propio Hernández, su hermosa "Elegía a la muerte de Ramón Sijé," el penúltimo poema construido de quince tercetos encadenados y un cuarteto, era su poema más hondo y personal. (No es de extrañar que en el entierro de su amigo Antonio Buero Vallejo - el 30 de abril de 2000 - se escucharon varios versos de esta misma "Elegía.") Se trata de la idea de que la única verdad que existe en su propia vida - y en la vida humana - es la muerte. El poema se refiere a su amigo 
DALE, S. Lo quevedesco y el poeta como hombre...

Sijé y está escrito de una forma cruda. La dicotomía principal en el poema es la de la vida y la muerte y este dualismo domina su visión amarga del mundo, una ostensible discordia anímica que revela su verdadero "yo". Las furiosas palabras de los tercetos décimo y undécimo (p. 119) revelan su frustración contra la muerte inevitable:

\author{
Quiero escarbar la tierra con los dientes, \\ quiero apartar la tierra parte a parte \\ a dentelladas secas y calientes. \\ Quiero minar la tierra hasta encontrarte \\ y besarte la noble calavera \\ y desamordazarte y regresarte.
}

Aquí los instintos de la vida están en oposición a los de la muerte; y esto es la dicotomía entre la autosatisfacción y la destrucción en la poética de El rayo. El hombre es tierra, como lo era en algunos de los mejores sonetos de Quevedo, y ser tierra es sinónimo de vida. Quiere decirse que el existir es -al final- morir. A diferencia de la poética idealizada del sonetista barroco, sin embargo, Hernández subraya la realidad íntima de la muerte de Sijé no como tránsito a una inmortalidad del espíritu personal, sino como una transformación personal de un hombre de carne y hueso. Es una aceptación sincera del destino humano y una actitud existencial frente a la muerte. Termina la "Elegía" con este cuarteto optimista (p. 119):
A las aladas almas de las rosas del almendro de nata te requiero, que tenemos que hablar de muchas cosas, compañero del alma, compañero.

Son unas palabras intimas sobre la muerte, el dolor y la nostalgia que sugieren una posible "primavera" -después del invierno-, la esperanza inalcanzable que algún día vuelva Sijé a los campos de Orihuela.

Hernández, entonces, también refunde la visión quevedesca de la muerte. En el ya mencionado "Himno a las estrellas" (1620), de Quevedo, por ejemplo, la descripción de la naturaleza persigue un efecto de sorpresa y asombro abstracto: 
Las tenebrosas aves, que el silencio embrazan con gemido, volando torpes y cantando graves, más agüeros que tonos al oído, para adular mis ansias y mis penas, ya mis musas serán, ya mis sirenas. (v. 67-72)

Este trozo nos sugiere el destino del hablante lírico: la muerte. Este amante universal y desconocido está harto de estar sólo en el mundo, y llega a la conclusión de que sus "ansias" y "penas" -la triste naturaleza del amor- ya son demasiadas. Así que ya no importa la identidad de la amada; lo importante es la "llama que a la inmortal vida transciende." Los últimos dos versos del "Himno"-"para adular mis ansias y mis penas / ya mis musas serán, ya mis sirenas" (v. 71-72)- son en realidad una finalidad retórica primaria, una elegía idealizada que se refiere a la mortalidad humana de la desconocida voz poética. Mientras que el hablante lírico en Quevedo queda elusivo, el de Hernández es el poeta mismo.

Por ejemplo, la conocida metáfora del "carnívoro cuchillo" -que aparece en el primer verso de $E l$ rayo- equivale al mismo corazón de Hernández, un corazón como amenaza a la muerte. Como ya ha señalado Joaquina Canoa Galiana (1993), este símbolo del cuchillo -empleado también en Bodas de sangre de Lorca-, representa el dolor del amor íntimo que queda planteado como destrucción personal, a la manera de Aleixandre (Canoa Galiana, p. 597-602). Coge su propio dolor, pena y alegría para trocarlos en material lírico; es decir, la pasión amorosa, la amenaza del "carnívoro cuchillo", su propio mundo poblado de ansiedades y, por supuesto, el rayo incesante que amenaza a su vida. Afirma Patrick Glairacq (1986) sobre la repetición de este perpetuo "rayo incesante":

La répetition quant á elle (conçue comme point de co-référence ayant quelque chose á voir avec le génotexte), elle s'informera dans cette instance de la signification par le ressort mimétique de la fiction lyrique qu'est la loquéle. C'est "la forme emphatique du discourir amoureux" á laquelle le Rayo que no cesa rend hommage dans un premier temps. (p. 136)

La epanáfora del símbolo de este "rayo" personal es buen ejemplo de la chisporroteante poesía hernandina y su espontánea combustión de metáforas, gracias verbales, asociaciones fulgurantes e inesperadas de la palabra viva. Como cualquier 
metáfora, la imagen hernandina expresa más que lo pensado. En una palabra, el símbolo del rayo ofrece un ejemplo de un ejercicio retórico y un indicio del ingenio del poeta murciano, pues aplicar optimamente las metáforas es indicar qué poeta es de primera fila y cuál de segunda. Cada detalle en El rayo nos entrega la clave para penetrar en el centro de la obra; y desde el centro siempre podemos echar una mirada a los demás detalles y comprobar si tal "étymon espiritual", si tal "raíz psicológica," explica el conjunto de lo que veíamos.

Hernández también refunde la visión abstracta de la pena en Quevedo. En el tercer movimiento del "Himno" del poeta barroco, por ejemplo, la voz lírica describe la rígida armonía del reino de las luces astrales, es decir las penas idealizadas del dominio amoroso del hablante lírico. El amor abstracto de las estrellas provee al universo el orden pero también impone cierto nivel de orden doloroso. Nótese el empleo de la homofonía de la vocal "a":

si amasteis en la vida

y ya en el firmamento estáis clavadas, pues la pena de amor nunca se olvida, (v. 49-51)

Los astros quevedescos emanan y relacionan el amor con la dureza, representada en su estructura astral, y las consecuencias amorosas, aunque sean abstractas e impersonales. La armonía de esta monarquía celeste mueve de la doctrina platónica a la armonía idealizada producida por la rotación de las esferas celestes como en otro poema conocido de Quevedo, "Las luces sacras, el augusto día":

Primeros mobles son vuestras esferas, que arrebatan en cerco ardiente de oro mis potencias absortas y ligeras. (Quevedo, 1990, p. 341)

Los movimientos de las "esferas de oro" coinciden con las aventuras amorosas del hombre universal (no el "yo" personal, o el individuo, como en Hernández) y la armonía entre los seres humanos depende no necesariamente de su propia voluntad sino de la rotación de las estrellas celestes. A diferencia de Hernández -un poeta profundamente íntimo y personal-, Quevedo es ante todo el poeta que mejor sabe expresar la inmanencia general del sufrimiento, la angustia universal y la melancolía amorosa. 
Esta visión quevedesca de la pena, entonces, es otro tema principal en $E l$ rayo que no cesa. La rebeldía en nuestra obra hernandina comienza al constatar que ciertos dolores no son obra de fatalidad, sino del hombre. Sumido en corazón herido y dentro del simbolismo esencial de la poesía está el "hombre entre bastidores," es decir, el propio Miguel Hernández. La concepción de su propio amor es como una tortura fatal y un destino trágico. Esto lo vemos en el segundo cuarteto y primer terceto del tercer soneto de El rayo (p. 92):

en el mío has entrado, y en él pones una red de raíces irritadas, que avariciosamente acaparadas tiene en su territorio sus pasiones.

Sal de mi corazón del que me has hecho un girasol sumiso y amarillo al dictamen solar que tu ojo envía

Tras las potentes imágenes de "la red de raíces irritadas" y el "sal del corazón", vemos que el dolor del amor personal de Hernández puede destruir la voz poética. Con prisa, urgido por la llama que le abrasa, su corazón canta los llantos del amor y la muerte. Dice en el primer terceto del decimonoveno soneto (p. 106):

\author{
Me callaré, me apartaré si puedo \\ con mi constante pena instante, plena, \\ a donde ni has de oírme ni he de verte.
}

Furiosa y dulcemente, el amor y la pena le sostienen, y su poesía es su resguardo. Por eso Hernández utiliza el soneto; se encrespa hacia un trasmundo trágico, el trasmundo de la sangre y con su destino humano en ella. En El rayo la pena queda vencida por la luz del optimismo, la muerte por la poesía. Por ejemplo, termina el sexto soneto con estas palabras relevadoras: "jcuánto penar para morirse uno!" (p. 94).

El soneto ejemplar del tema de la dureza de la pena en el propio Hernández es el segundo (p. 91-92), el que nos ofrece la resonancia de su interioridad angustiosa dentro de su sencillez poética: 
DALE, S. Lo quevedesco y el poeta como hombre...

¿No cesará este rayo que me habita

el corazón de exasperadas fieras

$y$ de fraguas coléricas $y$ herreras

donde el metal más fresco se marchita?

¿No cesará esta terca estalactita

de cultivar sus duras caballeras

como espadas y rígidas hogueras

hacia mi corazón que muge y grita?

Este rayo ni cesa ni se agota:

de mí mismo tomó su procedencia

y ejercita en mi mismo sus furores.

Esta obstinada piedra de mí brota

y sobre mí dirige la insistencia

de sus lluviosos rayos destructores.

En primer lugar, tenemos de nuevo el símbolo perpetuo de la pena, el "rayo de metal" que no cesa, y una metáfora semejante, la de la "terca estalactita" (Canoa Galiana, p. 597-602). Luego, en los últimos dos versos del segundo cuarteto, se nos ofrece una potente imagen de su propio corazón doloroso, que parece ser un corazón de un toro, una bestia que "muge" y "grita" para chillar su grave dolor (Hernández 1988, p. 111-112). El toro del vigésimosexto soneto -según Manuel Ruiz FunesFernández (1992)- es el símbolo de su propia existencia, lejos de los goces del amor (Ruiz Funes-Fernández, 1992, p. 414-419). Y esto es causa de los múltiples "rayos destructores" mencionados abajo en la sextina, la que responde a las dos preguntas en la octava de arriba. Como ya ha sostenido González Romano (1993), el corazón, su ser y su tortura a la vez, son hogar de su pena conmovedora y trágica (González Romano, p. 591-594). Las metáforas e imágenes del rayo, la "terca estalactita" y los "lluviosos rayos destructores" revelan sus propios sentimientos hirientes y dolorosos, su aceptación de la derrota de su corazón penoso, su dolor, sus gritos, su virilidad y su lucha frente al destino (Hernández, 1988, p. 92). El amor es causa de su autodestrucción, su fatal tortura y su trágico destino.

Se puede observar, entonces, que Hernández reinterpreta los mismos temas y símbolos barrocos encontrados en la poética de Quevedo. Por ejemplo, en el "Himno a las estrellas," las referencias al "zafir marchando," la imagen sensorial del "ejército de oro" en la segunda estrofa y la metáfora del "mar de luz" en la estrofa anterior, aluden, evidentemente, a lo cinético. La esencia misteriosa y abstracta 
del amor ("guardáis el trono del eterno coro" [v. 9] y "misteriosos encendidos" [v. 18]) se encuentra aquí como paralelo al grandioso concierto de los astros. Estos mismos astros son metáforas idealizadas para los ojos ("por cuyos ojos vela el mundo ciego" [v. 12]), y son la fuerza principal que gira el universo. La imaginación quevedesca interpreta las esferas misteriosas del mundo humano y las del mundo astronómico como un mismo ente (las "diversas escuadras militando" [v. 10]); los dos son reflejos mutuos de sí mismos. Así que la fuerza del amor en Quevedosiempre idealizada, impersonal y abstracta- es la base de la belleza humana pero, al mismo tiempo, la gran inspiración en la refundición intimista de Hernández.

En fin, es evidente la revisión "intimista y personal" de la poética quevedesca en $E l$ rayo que no cesa. Fue T. S. Eliot el que dijo que más importante que la originalidad temática de un escritor es su solidaridad con una forma colectiva, la de una cultura nacional, la de una tradición o sistema y, además, los poetas roban de otros. Y Northrop Frye indicó que la poesía solamente se puede hacer de otros poemas, que la literatura se hace a sí misma (Frye, 1952, p. 97). Y esto es lo que tenemos en Hernández: un temario castizo español, tomado de la lírica amorosa de Quevedo. He aquí el primer cuarteto del décimo soneto de $E l$ rayo (p. 97) que ilustra esta tradición amorosa tan rica en lamentos:

Tengo estos huesos hechos a las penas

y a las cavilaciones estas síenes:

pena que vas, cavilación que vienes

como el mar de la playa a las arenas.

Al final, se podría observar que casi todos los escritores derivan de alguna tradición. Por ejemplo, tenemos de nuevo la influencia quevedesca en el primer cuarteto del soneto vigésimotercero de $E l$ rayo (p. 109); nótese aquí en el primer verso su semejanza al primer verso de uno de los sonetos más conocidos de Quevedo que empieza con las palabras, "Para ti, que naciste al luto y llanto":

Como el toro he nacido para el luto, y el dolor, como el toro estoy marcado por un hierro infernal en el costado y por varón en la ingle con un fruto. 
DALE, S. Lo quevedesco y el poeta como hombre...

En pocas palabras, Miguel refunde y continúa con el lenguaje poético del siglo XVII y adapta un matiz nuevo, mucho más personal e intimista. Y por eso Hernández es sobre todo un artista consumado antes que un poeta inspirado, un joven escritor que vocé su propia alma de una manera íntima, con formas tradicionales.

Comparado con el "Himno" de Quevedo, entonces, El rayo es una obra tremendamente dolorosa, trágica y desesperada, es decir, un poemario autobiográfico. Miguel escribe con conciencia cuidada y en ella queda expresado en forma íntima el tema de la pena personal. Todo el poemario está en equilibrio inestable entre lo humano (los dolores) y lo inhumano (los símbolos), o entre el idilio y la tragedia. Es casi una obra existencialista, pues en ella hay una clara desesperación individual, una falta de esperanza y un tono amargo. Los primeros cuartetos de los sonetos decimotercero y decimocuarto (p. 100) expresa este vigor amargado de frialdad, soledad, tristeza y violencia:

Mi corazón no puede con la carga de su amorosa y lóbrega tormenta y hasta mi lengua eleva la sangrienta especie clamorosa que lo embarga.

Silencio de metal triste y sonoro, espadas congregando con amores en el final de huesos destructores de la región volcánica del toro.

Al final parece que la desolación es la "solución" a sus más íntimas cuestiones y dudas. Pero no quiere decirse que Hernández sea poeta de pensamiento filosófico. Más bien es un hombre de poética-intuición que hace las preguntas, "¿qué soy?" y “¿adónde voy?" En sus versos su propia vida humana aparece en toda su intensidad, de una autenticidad viril y descarada, y con un matiz apocalíptico. $Y$ según Frye (1952), "cuando el arte es apocalíptico, lo revela" (p. 125). Aquí el hombre se sabe vencido, pero como un héroe trágico griego, se crece en el dolor y en la adversidad, dándonos el ideal humano. Para él el fenómeno vital es esa lucha inútil, pero necesaria, del hombre contra fuerzas supremas como el destino, la pasión, el tiempo, la muerte y la pena (Arrigoitia, 1968, p. 31). Es una lucha necesaria porque en ella va envuelta su razón de ser y en ella logra el hombre su plenitud. En fin, esta poesía hernandina se declara en inexorable dialéctica entre la esperanzada nostalgia y la desesperada constatación del mundo. 
Al final, Hernández es uno de esos poetas de gracia y misterio, capaz de escribir sobre las angustias más íntimas del alma con una fuerte resonancia poética. (En este sentido también se podrían observar algunos matices posrománticos en Hernández, pues versa sobre los mismos síntomas y metáforas románticos encontrados en la poesía de Espronceda, Bécquer y Zorrilla.) Este alma, el soplo de la gran materia que es El rayo, es el reflejo inconsciente del incurable esteticismo romántico que Miguel sufría. Mientras que Quevedo describió los temas del amor y la pena desde una perspectiva analítica y abstracta, Hernández analiza el amor desde una postura mucho más íntima, personal y humana. Para el poeta barroco el amor y la pena son conceptos idealizados; para el poeta contemporáneo son fenómenos inseparables del alma humana. En la poética de Hernández -temáticamente relacionada con la poesía quevedesca-, lo que se pierda en originalidad o innovaciones técnicas se gana en sincera humanidad. $Y$ así cuando sólo nos queda su palabra, nos ha quedado, en ella, el hombre sin esperanzas de libertad que corre hacia lo que siente como propio: la tierra, la mujer y la muerte. Su poemario está lleno de sencillez y emoción, lo cual impera en toda su creación poética. Lo más sobresaliente es su autenticidad, su voluntad de logro, es decir, el testimonio de su caso humano. Miguel quiso ser poeta humano y lo fue. Su vocación poética es evidencia de un escritor de puro rigor mental. Después de su muerte en la cárcel en 1942, nos quedó su riquísima poesía y, sobre todo, El rayo que no cesa, una obra valiente que conviene tener muy en cuenta al establecer el balance de la poesía española contemporánea.

\section{RESUMEN}

En este estudio se analiza la visión del amor en El rayo que no cesa de Miguel Hernández (1910-1942), teniendo como referencia la poesía amorosa de Francisco de Quevedo (1580-1645). Mientras el poeta barroco ofrece una interpretación idealizada y abstracta del amor, el poeta contemporáneo expresa el amor a través de su propia pasión, su alma, su impulso creador y nos revela su intensa inspiración. El rayo que no cesa es principalmente una obra que desarrolla los temas corporales del amor, la pena y la muerte. Los factores más íntimos que salpican su poética -las muertes de Sijé, Manresa y, posiblemente, su primer hijo-, son las fuerzas que empujan a Hernández a imaginarse una poética tan profunda y emotiva.

Palavras-clave: Miguel Hernández, poesía contemporánea, Francisco de Quevedo, poesía amorosa. 
DALE, S. Lo quevedesco y el poeta como hombre...

\section{RESUMO}

Neste estudo, analisa-se a visão de amor em El rayo que no cesa, de Miguel Hernández (1910-1942), tendo como referência a poesia amorosa de Francisco de Quevedo (1580-1645). Enquanto o poeta barroco oferece uma interpretação idealizada e abstrata do amor, o poeta contemporâneo expressa o amor através de sua própria paixão, sua alma, seu impulso criador e revela sua intensa inspiração. El rayo que no cesa é principalmente uma obra que desenvolve os temas corporais de amor, pena e morte. Os fatores mais íntimos que salpicam a sua poética - a morte dos amigos Sijé e Manresa, e possivelmente, do seu primeiro filho -, são as forças que levam Hernández a imaginar uma poética tão profunda e emotiva.

Palavras-chave: Miguel Hernández, poesia contemporânea, Francisco de Quevedo, poesia amorosa.

\section{REFERÊNCIAS}

ACEREDA, A. El lenguaje poético de Miguel Hernández. Madrid: Pliegos, 1995.

Hipérbaton e hipérbole como rasgos neobarrocos en la poesía de Miguel Hemández. Monographic Review-Revista Monográfica, n. 10, p. 37-45, 1994.

ARrigoitia, L. Temas en la poesfa de Miguel Hernández. Puerto, n. 3, p. 20-33, 1968.

BALCELLS, J. M. Perspectiva petrarquista de El rayo que no cesa. Ínsula, n. 544, p. 17-18, 1992. CANO BALLESTA, J. La poesía de Miguel Hernández. Madrid: Gredos, 1971.

—. La renovación poética de los años treinta y Miguel Hernández. In: IFACH, M. G. (Ed.). Miguel Hernández. Madrid: Tauns, 1975.

CANOA GALIANA, J. Los símbolos de El rayo que no cesa. In: ROVIRA, J. C. (Coord.). Homenaje a Miguel Hernández, cincuenta años después. p. 597-602.

CASTILLA, A. Ferris fábula sobre la relación de Miguel Hernández con una mujer casada. El País Digital, 22 septiembre 2000. p. 1.

CHEVALLIER, M. Notas sobre la arquitectura poética de El rayo que no cesa. Insula, n. 544, p. 16-17, 1992.

DOMNGO, J. Miguel Hemández: la vida y la muerte. In: IFACH, M. G. (Ed.). Miguel Hernández. Madrid: Taurus, 1975. 
DALE, S. Lo quevedesco y el poeta como hombre...

FERRIS, J. L. El amor y la nada. Madrid: Planeta, 2000.

FRYE, N. Anatomy of criticism: Four Essays. Princeton, N. J.: Princeton University Press, 1952. GLAIRACQ, P. Sur El rayo que no cesa de Miguel Hernández. Imprévue, n. 4, p. 33-55, 1986.

GONZÁLEZ ROMANO, J. A. Unidad en El rayo que no cesa: imágenes del amor trágico. In: ROVIRA, J. C. (Coord.). Homenaje a Miguel Hernández, cincuenta años después. p. 591 595.

GUEREÑA, J. L. Miguel Hernández. Barcelona: Destino, 1983.

HERNÁNDEZ, M. El rayo que no cesa. Madrid: Espasa Calpe, 1988.

Antología poética. Valencia: Institución Alfons el Magnánim / Diputación de Valencia, 1999.

Antología. Madrid: Austral, 2000.

ROVIRA, J. C. (Coord.). Homenaje a Miguel Hernández, cincuenta años después. Alicante: Comisión del Homenaje a Miguel Hernández, 1993.

MARTINENGO, A. La astrología en la obra de Quevedo: una clave de lectura. Pamplona: Universidad de Navarra, 1992.

MICHAUD, G. Introduction á une science de la littérature. Istanbul: Pulhan Matbaasi, 1950.

ALEMANY, C. (Ed.). Miguel Hemández. Alicante: Fundación Cultural CAM, 1992.

MORA, M. Una extensa antología reivindica la gran poesía de Miguel Hernández. El País Digital, 14 febrero 2000. Cultura 1382, p. 1.

RODRÍGUEZ, A. G. Miguel Hernández: forma y contenido en la plenitud poética de El rayo que no cesa. Taller de Letras, n. 24, p. 129-147, 1996.

ROLON, A. Diálogos de discursos: lectura culturalista de tres poemas de Miguel Hemández. Letras Peninsulares, n. 7, p. 523-537, 1995.

RUIZ FUNES-FERNÁNDEZ, M. Sobre los sonetos del toro en El rayo que no cesa. In: REVENGA, F. J. D.; PACO, M. (Eds.). Estudios sobre Miguel Hernández. Murcia: Universidad de Murcia, 1992. p. 413-420.

OLIVARES, J. The Love Poetry of Francisco de Quevedo: an Aesthetic and Existential Study. Cambridge: Cambridge University Press, 1983.

PLATÓN. The Symposium and The Phaedo. Arlington Heights, IL: AHM, 1980.

QUEVEDO, F. Poesía original completa. Barcelona: Planeta, 1990.

SOBEJANO, G. La imaginación nocturna de Quevedo y su "Himno a las estrellas". In: IFFLAND, J. (Ed.). Quevedo in Perspective. Newark, DE: Juan de la Cuesta, 1980. p. 33-56.

VERSOS de Miguel Hernández despiden a Antonio Buero Vallejo. El País Digital, n. 1459, 1 mayo 2000. p. 1. 